\title{
Zur Frage der Fällbarkeit der Harnsäure und Purinbasen durch Zinksalze.
}

\author{
Von \\ E. Salkowski. \\ (Der Redaktion zugegangen arn 1. Das 1913.)
}

Herr Prof. M. Siegfried hat die Freundlichkeit gehabt, mich darauf aufmerksam zu machen, daß er die Fällbarkeit der Harnsäure durch Zinksalze bereits festgestellt habe, während diese Tatsache in der unter meiner Leilung ausgeführten Arbeit von Kojo') und namentlich von Kashiwabara ${ }^{2}$ ) als neu angesehen wird. Sicgfried bezieht sich auf eine in dieser Zeitschr., Bd. 24, S. 398 (1898) gemachte Bemerkung. Im 4. Abschnitte dieser Arbeit behandelt Siegfried die Frage, ob Urocaninsäure im menschlichen Harn vorkommt. 601 normaler menschlicher Harn und setwa ebensoviel , Harn von Gichtkranken wurden zur Untersuchung auf Urocaninsäure von Phosphorsäure befreit und dann mit Chlorzink gefällt. Es heißt alsdann 1. c. S. 409: «Die Zinkniederschlägen lieferten jedoch in keinem Falle Urocaninsäure. Sie enthalten fast die gesamte Harnsäure und Kreatinin.s Diese Beobachtung hat das Schicksal mancher anderer gelegentlich gemachten geteilt: sie ist weder in den Supplementband zu Bd. I von Beilstein (1901) noch in den Malyschen Jahresbericht, noch in das Chem. Centrbl. übergangen und damit für die weitere Forschung verloren gegangen, wie ich zu meinem Schaden habe erfahren müssen. Einen Vorwurf kann man mir meines Erachtens aus meiner Unkenntnis nicht machen, denn daß man eine jetzt 15 Jahre zurückliegende gelegentlich gemachte Bemerkung, die noch nicht eine Zeile umfaßt, im Kopfe haben müsse, wird niemand im Ernst verlangen. Die Priorität erkenne ich trotzdem gern an, wenn auch eine Angabe darüber fehlt, wie Siegfried sich von der nahezu vollständigen Ausfällung überzeugt hat.

Ich möchte bei dieser Gelegenheit noch erwähnen, daß auch die Purinbasen des Harns durch Zinksalze so gut wie vollständig gefällt werden. Die Belege hierfür sind in einer Arbeit mitgeteilt, die ich in den ersten Tagen des März an die Redaktion der Charité-Annalen abgeliefert habe. Da der betreffende Jahrgang erst im Oktober oder November zu erscheinen pflegt, schien es mir nicht überflüssig, diese Tatsache hier mitzuteilen, um einer Neuauffindung derselben vorzubeugen.

Endlich sei noch erwähnt, daß Zinksalze in konzentriertem saurem Harn einen spärlichen flockigen Niederschlag von Zinkphosphat geben, der allmählich krystallinisch wird und dann einer Harnsäureausscheidung, auch mikroskopisch, zum Verwechseln ähnlich sieht.

1) Diese Zeitschrift, Bd. 73, S. 416.

2) Daselbst, Bd. 84, S. 223. 